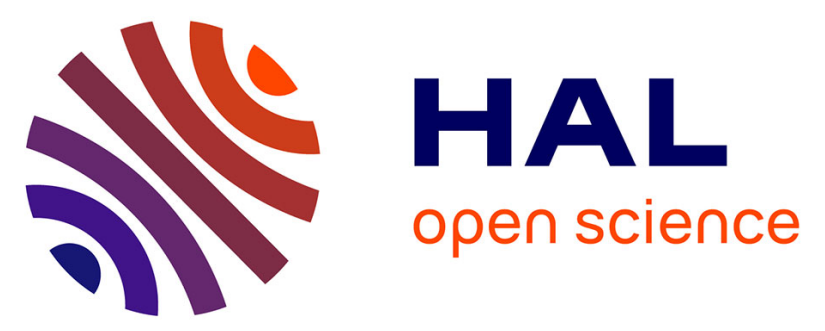

\title{
Clinical outcomes, radiologic kinematics, and effects on sagittal balance of the 6 df LP-ESP lumbar disc prosthesis
}

Jean-Yves Lazennec, Julien Even, Wafa Skalli, Jean-Patrick Rakover, Adrien Brusson, Marc-Antoine Rousseau

\section{To cite this version:}

Jean-Yves Lazennec, Julien Even, Wafa Skalli, Jean-Patrick Rakover, Adrien Brusson, et al.. Clinical outcomes, radiologic kinematics, and effects on sagittal balance of the 6 df LP-ESP lumbar disc prosthesis. Spine Journal, 2014, 14 (9), pp.1914-1920. 10.1016/j.spinee.2013.11.016 . hal-03273013

\section{HAL Id: hal-03273013 \\ https://hal.science/hal-03273013}

Submitted on 28 Jun 2021

HAL is a multi-disciplinary open access archive for the deposit and dissemination of scientific research documents, whether they are published or not. The documents may come from teaching and research institutions in France or abroad, or from public or private research centers.
L'archive ouverte pluridisciplinaire HAL, est destinée au dépôt et à la diffusion de documents scientifiques de niveau recherche, publiés ou non, émanant des établissements d'enseignement et de recherche français ou étrangers, des laboratoires publics ou privés. 


\title{
Clinical outcomes, radiologic kinematics, and effects on sagittal balance of the $6 \mathrm{df}$ LP-ESP lumbar disc prosthesis
}

\author{
Jean-Yves Lazennec, $\mathrm{MD}, \mathrm{PhD}^{\mathrm{a}, \mathrm{b}}$, Julien Even, $\mathrm{MD}, \mathrm{MS}^{\mathrm{a}}{ }^{\mathrm{b}}$, Wafa Skalli, $\mathrm{PhD}^{\mathrm{b}}$, \\ Jean-Patrick Rakover, $\mathrm{MD}^{\mathrm{c}}$, Adrien Brusson ${ }^{\mathrm{a}}$, Marc-Antoine Rousseau, MD, $\mathrm{PhD}^{\mathrm{b}, \mathrm{d}, *}$ \\ ${ }^{a}$ Department of Orthopaedic and Trauma Surgery, Pitié-Salpétrière Hospital, Assistance Publique-Hopitaux de Paris, 47-83 boulevard de l'hôpital, 75013 \\ Paris, France \\ biomechanics Lab, Arts et Métiers Paristech, 151 boulevard de l'hôpital, 75013 Paris, France \\ ${ }^{\mathrm{c}}$ Clinique du Pré, 13 Ave. René Laennec, 72018 Le Mans, France \\ ${ }^{\mathrm{d}}$ Department of Orthopaedic and Trauma Surgery, Avicenne Hospital, Assistance Publique-Hopitaux de Paris, 125 rue de Stalingrad, 93009 Bobigny,
}

France

\begin{abstract}
BACKGROUND CONTEXT: Surgical treatment of degenerative disc disease remains a contro-versial subject. Lumbar fusion has been associated with a potential risk of segmental junctional dis-ease and sagittal balance misalignment. Motion preservation devices have been developed as an alternative to fusion. The LP-ESP disc is a onepiece deformable device achieving $6 \mathrm{df}$, including shock absorption and elastic return. This is the first clinical report on its use.

PURPOSE: To assess clinical outcomes and radiologic kinematics in the first 2 years after implantation.

STUDY DESIGN: Prospective cohort of patients with LP-ESP total disc replacement (TDR) at the lumbar spine.

PATIENT SAMPLE: Forty-six consecutive patients.

OUTCOME MEASURES: Clinical outcomes were the visual analog scale (VAS) for pain, the Oswestry disability index (ODI), and the GHQ28 (General Health Questionnaire) psychological score. Radiologic data were the range of motion (ROM), sagittal balance parameters, and mean cen-ter of rotation (MCR).

METHODS: Patients had single-level TDR at L4-L5 or L5-S1. Outcomes were prospectively re-corded for 2 years (before and at 3, 6, 12, and 24 months after surgery). The SpineView software was used for computed analysis of the radiographic data. Paired $t$ tests were used for statistical comparisons. RESULTS: No intraoperative complication occurred. All clinical scores improved significantly at 24 months: the back pain VAS scores by a mean of 4.1 points and the ODI by 33 points. The aver-age ROM of the instrumented level was $5.4^{\circ} \pm 4.8^{\circ}$ at 2 years and more than $2^{\circ}$ for $76 \%$ of pros-theses. The MCR was in a physiological area in $73 \%$ of cases. The sagittal balance (pelvic tilt, sacral slope, and segmental lordosis) did not change significantly at any point of the follow-up. CONCLUSIONS: Results from the 2-year follow-up indicate that LP-ESP prosthesis recreates lumbar spine function similar to that of the healthy disc in terms of ROM, quality of movement, effect on sagittal balance, and absence of modification in the kinematics of the upper adjacent level. (C) 2014 Elsevier Inc. All rights reserved.
\end{abstract}

Keywords: $\quad$ Lumbar spine; Total disc replacement; Degenerative disc disease; Back pain; Mean center of rotation; Sagittal balance

FDA device/drug status: Investigational (ESP lumbar disc prosthesis [Fournitures Hospitalieres company]).

Author disclosures: $\boldsymbol{J}-\boldsymbol{Y L}$ : Consulting: FH (B). $\boldsymbol{J E}$ : Nothing to disclose. WS: Nothing to disclose. J-PR: Consulting: FH (B). AB: Nothing to disclose. $\boldsymbol{M}$-AR: Consulting: Stryker (B).

Conflict of interest: The first author has been consulting for the FH Company, which is the manufacturer of the LP-ESP disc prosthesis.

\footnotetext{
* Corresponding author. Service de Chirurgie Orthopédique et Traumatologique, Hôpital Avicenne-Assistance Publique Hôpitaux de Paris, 125 rue de Stalingrad, 93009 Bobigny, France. Tel.: (33) 1189553 11; fax: (33) 118955319 .

E-mail address: marc-antoine.rousseau @avc.aphp.fr (M.-A. Rousseau)
} 


\section{Introduction}

Degenerative disc disease (DDD) has become an important public health problem of multiple dimensions because of its impairment of patients' personal, social, and work life. This disease is still a medical and surgical challenge, especially because present therapeutic strategies remain controversial. The first approach is a conservative treatment that is mostly based on physical therapy, but persistent symptomatic DDD may be treated surgically in selected patients [1-3]. Lack of pain relief, loss of motion, pseudarthrosis, sagittal balance misalignment, bone graft donor site morbidity, and adjacent segment disease are pitfalls of intervertebral fusion [4] that suggested the development of total disc replacement (TDR).

Since 1966 and Farnström's first TDR implantation [5], many designs and concepts have been proposed [6]. The most commonly used devices are articulated implants and their mobility depends on the designs of the bearing surfaces. Ball-and-socket two-piece prostheses have $3 \mathrm{df}$ in every rotation around a single fixed center of rotation. Three-piece devices allow additional translations and provide 5 df. Articulated TDRs have demonstrated their clinical relevance in several series [7-10]. Specifically, the noninferiority of TDR versus fusion is now well accepted. Nonetheless, in vitro testing of the two types of implants has revealed that both designs have biomechanical advantages and limitations [11].

Because the native intervertebral disc is a deformable elastic structure with 6 degrees of freedom, a deformable elastic one-piece prosthesis would theoretically be the most physiological intervertebral implant. However, one remembers the former deformable Acroflex prosthesis (Depuy Acromed Inc, Warsaw, IN, USA) [12] with only 28 devices implanted due to the early failure of the elastic rubber in vivo [13]. The LP-ESP (Fig. 1) has been developed over the past 20 years at the Pierre and Marie Curie University (UPMC), the French Atomic and Alternative Energies Commission (CEA), and the Fournitures Hospitalière company (Fournitures Hospitaliere, Quimper, France). Improvements in technology have made it possible to solve the problem of the bond

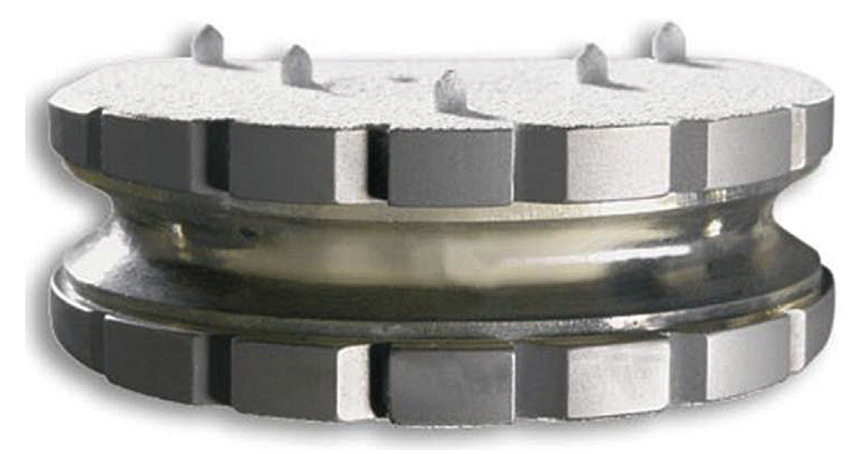

Fig. 1. One-piece deformable LP-ESP disc prosthesis: front view. between the elastic component and the titanium end plates. After successful in vitro testing, the LP-ESP (Fournitures Hospitalière) has been authorized for use in patients since 2005. We recently presented the biomechanical features of the ESP lumbar disc prosthesis and the long-term results of our pioneer experience up to 7 years follow-up [14].

The goal of the present study was focused on the functioning of LP-ESP in the first 2 years after implantation. Clinical results and radiologic outcomes were collected prospectively. In addition to range of motion (ROM), we were specifically interested in the quality of the kinematics and thus, investigated the mean center of rotation (MCR) at the instrumented and adjacent levels. Adaptation of spinal posture was also a major point of the study.

\section{Materials and methods}

\section{Implant design}

The LP-ESP (elastic spine pad) is a one-piece deformable implant made of silicone gel with micro voids and surrounded by polycarbonate polyurethane securely fixed to titanium end plates. The end plates have five anchoring pegs to provide primary fixation and are covered by hydroxyapatite to provide optimal bone ingrowth (Fig. 1). This geometry allows limited rotation and translation with elastic return that helps prevent overloading the posterior facet joints. The center of rotation can vary freely during motion. The viscoelastic prosthesis achieves $6 \mathrm{df}$ including vertical translation; it serves as a cushion and may allow shock absorption. The LP-ESP prosthesis thus differs notably from other current prostheses that are two- or threepiece devices that have one or two bearing surfaces and provide 3 or $5 \mathrm{df}$, very little or no resistance, and no elastic return. The LP-ESP thus has mechanical properties close to those of a natural disc [15].

\section{Population}

This study reports 46 consecutive cases of single-level TDRs implanted between October 2006 and April 2008 by two spine surgeons (JYL and JPR) in 18 men and 28 women (mean age at surgery, 42 years; range, 30-60 years). Their mean body mass index was 24 (range, 18.7-30.8).

The patients had had DDD for an average of 28 months (range, 12-42 months). Surgery was decided upon for symptomatic DDD only after the failure of nonsurgical treatment. Seventeen patients had at least one previous operation, including discectomies, partial laminectomies, and one internal fixation for burst fracture of L2. All patients had a preoperative magnetic resonance imaging of the lumbar spine and provocative discography (which was but no longer is a routine procedure in our practice) to assess the role of the disc as the pain generator. The absence of lumbar instability and facet arthritis were verified as eligibility criteria for the TDR procedure. 


\section{Surgical procedure}

The prosthesis was implanted through a left-sided mini anterior retroperitoneal approach as described by Lazennec et al. [16]. The level of implantation was L5-S1 in 25 cases and L4-L5 in 21. Three L4-L5 patients required a concomitant anterior L5-S1 fusion. The mean operative time was 69 minutes. The average blood loss was $75 \mathrm{~mL}$.

The postoperative recommendations were aimed at facilitating the optimum bone/hydroxyapatite implant fixation. They included the use of a lumbar belt for a month to help limit physical activity and stated that physical therapy was contraindicated.

\section{Clinical evaluation}

The clinical evaluation was prospectively recorded. The time points were the preoperative examination and at 3,6, 12 , and 24 months after surgery. The intensity of back pain was evaluated with a visual analog scale (VAS). Disability was assessed with the Oswestry Disability Index (ODI) [17] and psychological distress with the GHQ28 [18].

\section{Radiographic evaluation}

Radiographs of the lumbar spine were prospectively collected for the study before and 12 and 24 months after surgery. The X-ray films were digitalized with the VXR12 scanner (Vidar System Corporation, Herndon, VA, USA) and analyzed with SpineView software (Surgiview Corporation, Paris, France), the precision and reliability of which has previously been reported [19]. This analysis was performed by a single observer who was not involved in patient selection, surgical procedures, or follow-up examinations. The analysis included only strictly lateral views.

Kinematic parameters were studied at the level of implantation and the adjacent upper level on the flexion/extension X-rays. The ROM described the angular mobility quantitatively. Given that Champain et al. [19] reported $2^{\circ}$ accuracy for ROM measurement with SpineView, we considered that the prosthesis had no motion if the measured ROM was less than $2^{\circ}$. The MCR was noted for a qualitative assessment of the motion of the mobile levels, as previously described. An orthogonal coordinate system centered at the posterior superior corner of the lower vertebra, with the $\mathrm{x}$ axis along the posterior wall and the $\mathrm{y}$ axis along the end plate was used to describe the location of the MCR. The percentage of MCRs in a physiological location was determined as described by Tournier et al. [20].

Lateral views in standing position (lumbar spine including femoral heads) were used to assess sagittal balance, as defined by Duval-Beaupere et al. [21]:

- Sacral slope (SS): angle between the end plate of S1 and the horizontal plane.

- Pelvic tilt (PT): the angle between the vertical plane and the line connecting the center of the S1 end plate to the center of the femoral head. The midpoint of the line connecting the two femoral heads was used when those were not exactly superposed.

- Segmental lordosis (SL): the angle between the upper end plate of the superior vertebra and the lower end plate of the inferior vertebra (for L5-S1, the upper L5 end plate and the upper S1 end plate).

\section{Statistical analysis}

The means and standard deviations of the clinical and radiologic variables were calculated at each time point. Comparisons over time were assessed with paired $t$ tests. Significance was defined as $\mathrm{p}<.05$.

\section{Results \\ Clinical outcomes}

During the follow-up we observed no device failures, no major complications, and no neurologic deterioration. Table 1 summarizes the clinical outcomes at each followup. The ODI significantly improved between the preoperative and the 3-month postoperative assessments, between the 3- and 6-month postoperative assessments, and then stabilized. The VAS and the GHQ28 significantly improved at 3 months and remained stable thereafter.

\section{Sagittal alignment}

The course over time of the radiologic parameters of sagittal balance is reported in Table 2. Patients had no major disorders in this balance before or after TDR. Variations in SS and PT were not significant. The SL significantly increased for about $10^{\circ}$ after implantation and remained stable afterward.

\section{Kinematics analysis}

\section{Range of motion}

The average ROM in flexion/extension at the 2-year follow-up was $5.4^{\circ} \pm 4.2^{\circ}$ (Table 3 ). With mobility defined by the $2^{\circ}$ cutoff point, $66 \%$ of cases were mobile at 12 months and $76 \%$ at 24 months. The ROM of the replaced disc and the adjacent upper level did not change significantly between the different time points.

\section{Mean center of rotation}

Figures 2 (all cases) and 3 (one example) present the (x, y) coordinates of the MCRs with a ROM greater than $2^{\circ}$ at the instrumented level and the upper adjacent level. The mean X-MCR values at the instrumented level were $45.2 \% \pm 63.1 \%$ before surgery, $44.2 \% \pm 43.9 \%$ a year later, and $47.7 \% \pm 51.2 \%$ at 2 years, and the corresponding mean $\mathrm{y}-\mathrm{MCR}$ values were $-10.7 \% \pm 71.3 \%, 19.0 \% \pm 43.2 \%$, and $15.2 \% \pm 61.8 \%$, respectively. The corresponding mean $\mathrm{x}-$ MCR values at the upper adjacent level were $38.4 \%$ 
Table 1

Clinical outcomes over time (mean \pm SD)

\begin{tabular}{|c|c|c|c|c|c|}
\hline & Preop & $3 \mathrm{mo}$ & $6 \mathrm{mo}$ & $12 \mathrm{mo}$ & $24 \mathrm{mo}$ \\
\hline VAS & $6.5 \pm 1.9$ & $\begin{array}{l}2.3 \pm 1.2 \\
\quad \text { vs. } \text { p }_{\text {preop }}<.001\end{array}$ & $\begin{array}{l}2.1 \pm 1.6 \\
\text { vs. } \mathrm{p}_{\text {preop }}<.001 \\
\text { vs. } \mathrm{p}_{3 \mathrm{mo}}=.701\end{array}$ & $\begin{array}{l}2.1 \pm 1.6 \\
\quad \text { vs. } p_{\text {preop }}<.001 \\
\text { vs. } p_{6 \mathrm{mo}}=.316\end{array}$ & $\begin{array}{l}2.4 \pm 2.0 \\
\quad \text { vs. } \mathrm{p}_{\text {preop }}<.001 \\
\text { vs. } \mathrm{p}_{12 \mathrm{mo}}=.316\end{array}$ \\
\hline ODI & $40.8 \pm 12.5$ & $\begin{array}{l}18.8 \pm 10.6 \\
\text { vs. } \text { p }_{\text {preop }}<.001\end{array}$ & $\begin{array}{l}13.1 \pm 10.5 \\
\text { vs. } \mathrm{p}_{\text {preop }}<.001 \\
\text { vs. } \mathrm{p}_{3 \mathrm{mo}}=.003\end{array}$ & $\begin{array}{l}11.7 \pm 10.0 \\
\text { vs. } p_{\text {preop }}<.001 \\
\text { vs. } p_{6 \mathrm{mo}}=.288\end{array}$ & $\begin{array}{l}11.8 \pm 10.4 \\
\text { vs. } \mathrm{p}_{\text {preop }}<.001 \\
\text { vs. } \mathrm{p}_{12 \mathrm{mo}}=.858\end{array}$ \\
\hline GHQ28 & $60.5 \pm 14.5$ & $\begin{array}{l}45.2 \pm 9.2 \\
\quad \text { vs. } p_{\text {preop }}<.001\end{array}$ & $\begin{array}{l}46.1 \pm 12.5 \\
\text { vs. } \mathrm{p}_{\text {preop }}<.001 \\
\text { vs. } \mathrm{p}_{3 \mathrm{mo}}=.210\end{array}$ & $\begin{array}{l}42.9 \pm 14.2 \\
\text { vs. } p_{\text {preop }}<.001 \\
\text { vs. } p_{6 \mathrm{mo}}=.187\end{array}$ & $\begin{array}{l}44.0 \pm 7.8 \\
\text { vs. } \mathrm{p}_{\text {preop }}<.001 \\
\text { vs. } \mathrm{p}_{12 \mathrm{mo}}=.916\end{array}$ \\
\hline
\end{tabular}

SD, standard deviation; VAS, visual analog scale; ODI, Oswestry disability index; preop, preoperative; GHQ28, Global Health Questionnaire.

Note: All parameters significantly improved after implantation. Statistical comparisons showed the VAS and GHQ28 reached a plateau at 3 months and the ODI stabilized at 6 months.

$\pm 30.1 \%$ before surgery, $37.9 \% \pm 21.2 \%$ at 1 year, and $40.2 \% \pm 96.5 \%$ at 2 years, and the mean y-MCR values were $-7.5 \% \pm 123.8 \%, \quad 0.5 \% \pm 18.9 \%$, and $-7.4 \%$ $\pm 32.1 \%$, respectively.

At the instrumented level, the MCR location was physiological in $70 \%$ of mobile cases before surgery, $76 \%$ at 12 months, and $73 \%$ at 24 months and at the upper adjacent level in $89 \%, 100 \%$, and $90 \%$ of cases, respectively.

\section{Discussion}

In this study, we investigated the clinical outcomes and the radiologic postural and kinematic behavior of the LPESP lumbar disc prosthesis over the first 2 years after implantation. The clinical data show an early and stable improvement of clinical status. The radiologic data show the preservation of ROM at the instrumented and adjacent levels and the self-adaptation of the SS. Three quarters of the patients had physiological mobility at the instrumented level after 2 years of follow-up, with secondary self adjustment of the center of rotation in flexion/extension.

We acknowledge that this is a very preliminary work, as the safety of the new prothesis cannot be estimated to any real degree with the numbers included. While one recent

Table 2

Radiologic parameters in standing position over time (mean \pm SD)

\begin{tabular}{|c|c|c|c|}
\hline & Preop & $12 \mathrm{mo}$ & $24 \mathrm{mo}$ \\
\hline Pelvic incidence & $48.3^{\circ} \pm 11.3^{\circ}$ & & \\
\hline Sacral slope & $34.0^{\circ} \pm 8.9^{\circ}$ & $\begin{array}{l}34.3^{\circ} \pm 10.0^{\circ} \\
\quad \text { vs. } p_{\text {preop }}=.101\end{array}$ & $\begin{aligned} 35.3^{\circ} \pm 9.7^{\circ} & \\
\text { vs. } \mathrm{p}_{\text {preop }} & =.080 \\
\text { vs. } \mathrm{p}_{12 \mathrm{mo}} & =.842\end{aligned}$ \\
\hline Pelvic tilt & $14.2^{\circ} \pm 5.7^{\circ}$ & $\begin{array}{l}11.4^{\circ} \pm 7.1^{\circ} \\
\quad \text { vs. } p_{\text {preop }}=.118\end{array}$ & $\begin{array}{l}12.9^{\circ} \pm 6.3^{\circ} \\
\text { vs. } \mathrm{p}_{\text {preop }}=.306 \\
\text { vs. } \mathrm{p}_{12 \mathrm{mo}}=.975\end{array}$ \\
\hline Segmental lordosis & $15.6^{\circ} \pm 7.3^{\circ}$ & $\begin{array}{l}25.8^{\circ} \pm 5.8^{\circ} \\
\text { vs. p preop }<.001\end{array}$ & $\begin{array}{l}25.4^{\circ} \pm 5.7^{\circ} \\
\quad \text { vs. } \mathrm{p}_{\text {preop }}<.001 \\
\text { vs. } \mathrm{p}_{12 \mathrm{mo}}=.196\end{array}$ \\
\hline
\end{tabular}

SD, standard deviation; preop, preoperative.

Note: Sacral slope and PT did significantly change between the preoperative assessment and the other time points. The SL significantly increased after implantation and remained stable afterward. article from the designers reports a series of patients with 7 years follow-up [14], more studies from authors without conflict of interest, presenting more patients and longer follow-ups would obviously be useful for assessing longterm reliability. Nonetheless, the present study reports the outcomes that the surgeon and patient can expect during the first 2 years from the innovative LP-ESP implant and provides the first data for it.

VAS scores improved in this series of patients by a mean of 4.1 points and the ODI by 29 points. These encouraging results are basically similar to the clinical results reported by Tropiano et al. [22] with the Prodisc II ( 6 and 28 points, respectively [Synthes, West Chester, PA, USA]). The significant improvement of the GHQ28 at 3 months indicates a rapid alleviation of psychological symptoms, whereas the ODI improved more progressively but throughout the entire first year.

The preoperative radiologic parameters for spinal posture showed no major imbalance in comparison with the general population [23]. Sacral slope and PT did not change significantly after implantation. We note, however, that SL tended to increase, consistent with reports in the literature for articulated prostheses $[20,24,25]$. Specifically, Chung et al. [25] and Tournier et al. [20] both reported a significant

Table 3

Range of motion of the prosthesis and the upper adjacent disc (mean \pm SD)

\begin{tabular}{|c|c|c|c|}
\hline & Preop & $12 \mathrm{mo}$ & $24 \mathrm{mo}$ \\
\hline \multicolumn{4}{|l|}{ Prosthetic level } \\
\hline ROM & $6.7^{\circ} \pm 5.4^{\circ}$ & $\begin{array}{l}4.6^{\circ} \pm 4.8^{\circ} \\
\quad \text { vs. } p_{\text {preop }}=.192\end{array}$ & $\begin{array}{l}5.4^{\circ} \pm 4.2^{\circ} \\
\quad \text { vs. } \mathrm{p}_{\text {preop }}=.173 \\
\text { vs. } \mathrm{p}_{12 \mathrm{mo}}=.153\end{array}$ \\
\hline $\begin{array}{l}\text { Percentage of } \\
\text { mobile disc }\end{array}$ & 77 & 66 & 76 \\
\hline \multicolumn{4}{|c|}{ Upper adjacent level } \\
\hline $\mathrm{ROM}$ & $7.2^{\circ} \pm 6.2^{\circ}$ & $\begin{array}{l}8.9^{\circ} \pm 5.5^{\circ} \\
\quad \text { vs. } \text { p }_{\text {preop }}=.100\end{array}$ & $\begin{array}{l}8.3^{\circ} \pm 5.4^{\circ} \\
\quad \text { vs. } \mathrm{p}_{\text {preop }}=.762 \\
\text { vs. } \mathrm{p}_{12 \mathrm{mo}}=.649\end{array}$ \\
\hline $\begin{array}{l}\text { Percentage of } \\
\text { mobile disc }\end{array}$ & 65 & 79 & 85 \\
\hline
\end{tabular}

SD, standard deviation; ROM, range of motion; preop, preoperative. Note: No significant variations over time. 

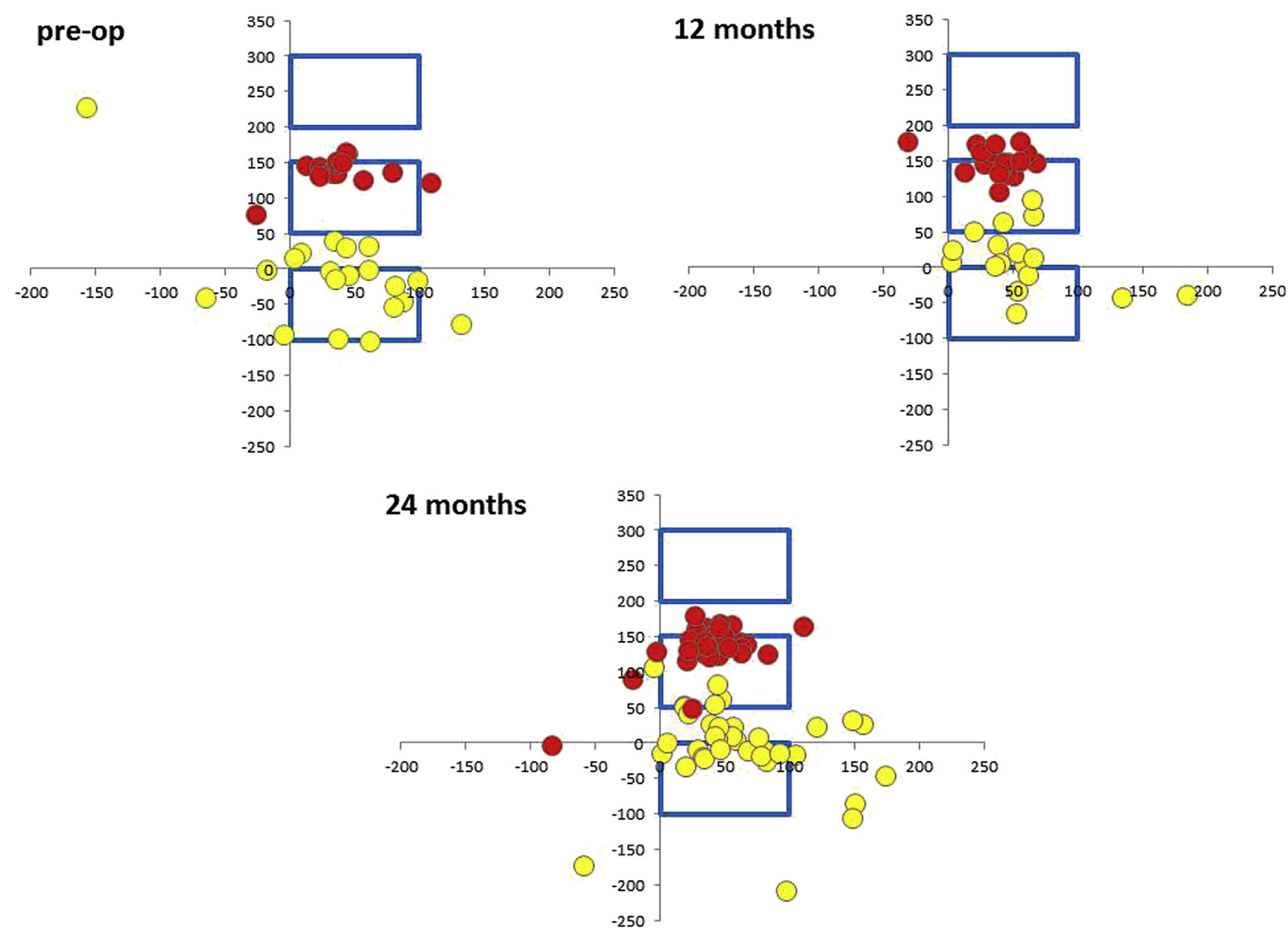

Fig. 2. Schematic diagram of the location of the mean center of rotation (MCR) at the instrumented $(O)$ and the upper adjacent $(O)$ levels (Top Left: preop; Top Right: 12 months postoperative; Bottom: 24 months postoperative). The MCR of the adjacent level remained in a physiological area throughout the follow-up period. The MCR of the prostheses tended to return toward the physiological area between 12 and 24 months. preop, preoperation.

increase in lumbar lordosis after implantation $\left(10.3^{\circ}\right.$ and $2.1^{\circ}$ respectively). In those studies, however, neither SS nor PT demonstrated any pelvic adaptation. This difference may be attributable to differences in population characteristics. We note here that no publication reports any sagittal misalignment after prosthetic implantation, whereas lumbar fusion may deleteriously alter the sagittal balance of the spine, including a decrease in SS and lumbar lordosis [26]. The increased SL could be related to the lordotic shape of the prosthesis, but probably also to the fact that arthroplasty, contrary to fusion, enables the lumbar spine to find a new balance spontaneously. It has not yet been demonstrated, however, that this self-adaptation of sagittal balance plays any protective role against adjacent-level degeneration.

The preservation or restoration of some mobility with a TDR (as opposed to arthrodesis) is intended to limit or prevent extension of the disease to adjacent levels. However, the optimal ROM for this purpose after TDR has not yet been defined. Huang et al. [27] reported measurements in a series of 42 Prodisc I implantations at a mean of 8.7 years after surgery: $24 \%$ of the junctional levels showed radiologic signs of degeneration. The mean ROM of the disc prostheses adjacent to the junctional disease was significantly lower than the mean ROM of the prostheses adjacent to a radiologically normal disc, ie, $1.6^{\circ}$ versus $4.7^{\circ}$. No patients with a ROM of $5^{\circ}$ or more had junctional degeneration, whereas $35 \%$ of those with less than $5^{\circ}$ motion did. On the other hand, $65 \%$ of patients with ROM less than $5^{\circ}$ did not develop adjacent segmental degeneration, so the authors did not conclude that $5^{\circ}$ was the trigger value for avoiding such degeneration. With a mean ROM of $5.4^{\circ}$ in flexion/extension (ie, $76 \%$ of prostheses mobile by more than $2^{\circ}$ ) in the present series, the LP-ESP device provides a level of mobility similar to that with articulated prostheses such as Prodisc, for which ROM varies according to the series from $3.8^{\circ}$ to $13.2^{\circ}$ [25,27]. We must note, however, that assessment of spinal kinematics with static $\mathrm{X}$-rays in flexion/extension can produce biased same-day variations [28] because the patient's effort during flexion/ extension is not always consistent. Nonetheless, flexion/extension X-rays are easily available and less irradiating than continuous motion analysis with in vivo fluoroscopy. 


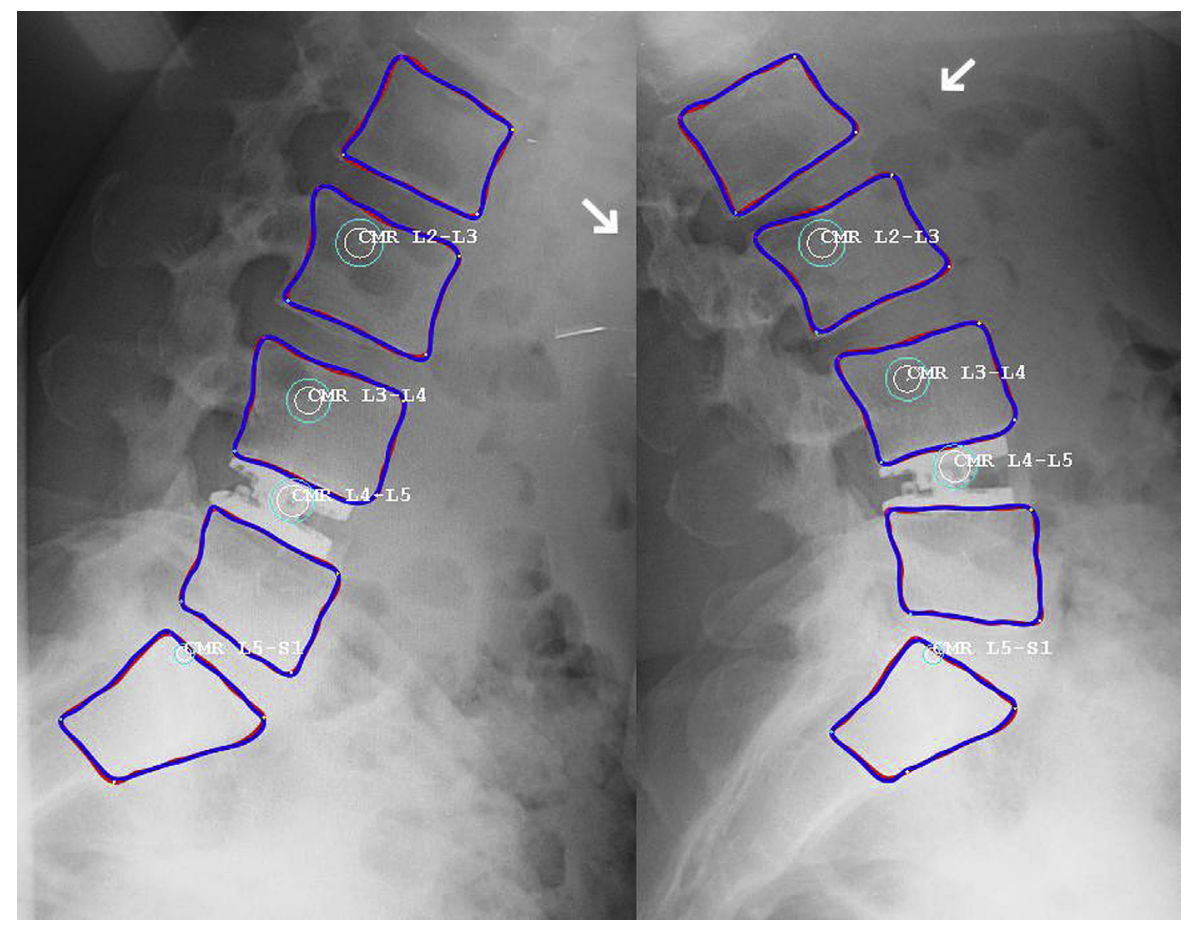

Fig. 3. Measurement of the MCR at the instrumented and at the upper adjacent levels in flexion/extension with SpineView. MCR, mean center of rotation; arrow, direction of the bending.

Quality of movement is also an issue. The LP-ESP is a novel one-piece deformable but cohesive interbody spacer providing $6 \mathrm{df}$ around the three axes. This allows the instantaneous axis of rotation to change freely, as in the normal disc, while preventing the overloading of the facets. The MCR, initially defined by Pearcy and Bogduk [29], is the pivot point about which a vertebra appears to move and is considered to reflect the quality of movement of a segment. With the development of discal arthroplasty, it appears to be an informative parameter for studying the quality of spinal movement imposed by a prosthesis [30]. The coordinates of the MCR for the LP-ESP prosthesis appear similar to those of the natural disc described in the literature. After 2 years of follow-up, the MCR was in a physiological location in $73 \%$ of cases in our study. Using the same methods, Tournier et al. [20] reported a "correct" MCR for 51\% of the Maverick (Medtronic Inc, Minneapolis, MN, USA) and $66 \%$ of the Prodisc prostheses.

\section{Conclusion}

The concept of the LP-ESP prosthesis differs from that of the articulated devices currently used in the lumbar spine; it allows $6 \mathrm{df}$ with elastic return and is intended to minimize change in the spontaneous instantaneous axis of rotation and reduce facet forces. The results from this series of 46 patients provide encouraging clinical results, kinematic behavior, and radiologic sagittal balance after implantation of the LP-ESP.
At the 2-year follow-up, mobility was maintained in $76 \%$ of cases with a mean flexion/extension ROM of $5.4^{\circ}$ and the MCR was in a physiological location in $73 \%$ of cases. The sagittal balance showed appropriate selfadaptation. Obviously, the reliability of the LP-ESP prosthesis shall be investigated in long-term studies for assessing the safety and the mechanical properties after a long while in vivo. Larger cohorts are also necessary for truly estimating the risk of failure of the LP-ESP device based on a sufficient number of cases. The main strong conclusion from these promising preliminary results is that it is reasonable to study it further.

\section{References}

[1] Blumenthal SL, Baker J, Dossett A, et al. The role of anterior lumbar fusion for internal disc disruption. Spine 1988;13:566-9.

[2] Moore KR, Pinto MR, Butler LM. Degenerative disc disease treated with combined anterior and posterior arthrodesis and posterior instrumentation. Spine 2002;27:1680-6.

[3] Fritzell P, Hagg O, Wessberg P, et al. 2001 Volvo Award Winner in Clinical Studies: Lumbar fusion versus nonsurgical treatment for chronic low back pain: a multicenter randomized controlled trial from the Swedish Lumbar Spine Study Group. Spine 2001;26:2521-32; discussion 2532-4.

[4] Boden SD, Balderston RA, Heller JG, et al. An AOA critical issue. Disc replacements: this time will we really cure low-back and neck pain? J Bone Joint Surg Am 2004;86-A:411-22.

[5] Fernstrom U. Arthroplasty with intercorporal endoprothesis in herniated disc and in painful disc. Acta Chir Scand Suppl 1966;357:154-9.

[6] Galbusera F, Bellini CM, Zweig T, et al. Design concepts in lumbar total disc arthroplasty. Eur Spine J 2008;17:1635-50. 
[7] Yaszay B, Bendo JA, Goldstein JA, et al. Effect of intervertebral disc height on postoperative motion and outcomes after ProDisc-L lumbar disc replacement. Spine 2008;33:508-12; discussion 513.

[8] Tropiano P, Huang RC, Louis CA, et al. Functional and radiographic outcome of thoracolumbar and lumbar burst fractures managed by closed orthopaedic reduction and casting. Spine 2003;28:2459-65.

[9] Le Huec JC, Mathews H, Basso Y, et al. Clinical results of Maverick lumbar total disc replacement: two-year prospective follow-up. Orthop Clin North Am 2005;36:315-22.

[10] David T. Long-term results of one-level lumbar arthroplasty: minimum 10-year follow-up of the CHARITE artificial disc in 106 patients. Spine 2007;32:661-6.

[11] Rousseau MA, Bradford DS, Bertagnoli R, et al. Disc arthroplasty design influences intervertebral kinematics and facet forces. Spine J 2006;6:258-66.

[12] Enker P, Steffee A, McMillin C, et al. Artificial disc replacement Preliminary report with a 3-year minimum follow-up. Spine 1993;18:1061-70.

[13] Fraser RD, Ross ER, Lowery GL, et al. AcroFlex design and results. Spine J 2004;4:245S-51S.

[14] Lazennec JY, Aaron A, Brusson A, et al. The LP-ESP((R)) lumbar disc prosthesis with 6 degrees of freedom: development and 7 years of clinical experience. Eur J Orthop Surg Traumatol 2013;23:131-43.

[15] Lazennec JY, Aaron A, Brusson A, et al. The LP-ESP lumbar disc prosthesis with 6 degrees of freedom: concept and design, functional specifications and clinical results after 8 years of pioneering experience. Eur J Orthop Surg Traumatol 2013;23:131-43.

[16] Lazennec JY, Pouzet B, Ramare S, et al. Anatomic basis of minimal anterior extraperitoneal approach to the lumbar spine. Surg Radiol Anat 1999;21:7-15.

[17] Page SJ, Shawaryn MA, Cernich AN, et al. Scaling of the revised Oswestry low back pain questionnaire. Arch Phys Med Rehabil 2002;83:1579-84.

[18] de Mont-Marin F, Hardy P, Lepine JP, et al. Validation of a French version of the General Health Questionnaire (GHQ-28) in a diabetic population [French]. Encephale 1993;19:293-301.
[19] Champain S, Benchikh K, Nogier A, et al. Validation of new clinical quantitative analysis software applicable in spine orthopaedic studies. Eur Spine J 2006;15:982-91.

[20] Tournier C, Aunoble S, Le Huec JC, et al. Total disc arthroplasty: consequences for sagittal balance and lumbar spine movement. Eur Spine J 2007;16:411-21.

[21] Duval-Beaupere G, Schmidt C, Cosson P. A Barycentremetric study of the sagittal shape of spine and pelvis: the conditions required for an economic standing position. Ann Biomed Eng 1992;20:451-62.

[22] Tropiano P, Huang RC, Girardi FP, et al. Lumbar disc replacement: preliminary results with ProDisc II after a minimum follow-up period of 1 year. J Spinal Disord Tech 2003;16:362-8.

[23] Guigui P, Levassor N, Rillardon L, et al. Physiological value of pelvic and spinal parameters of sagittal balance: analysis of 250 healthy volunteers [French]. Rev Chir Orthop Reparatrice Appar Mot 2003;89:496-506.

[24] Le Huec J, Basso Y, Mathews H, et al. The effect of single-level, total disc arthroplasty on sagittal balance parameters: a prospective study. Eur Spine J 2005;14:480-6.

[25] Chung SS, Lee CS, Kang CS, et al. The effect of lumbar total disc replacement on the spinopelvic alignment and range of motion of the lumbar spine. J Spinal Disord Tech 2006;19:307-11.

[26] Lazennec JY, Ramare S, Arafati N, et al. Sagittal alignment in lumbosacral fusion: relations between radiological parameters and pain. Eur Spine J 2000;9:47-55.

[27] Huang RC, Tropiano P, Marnay T, et al. Range of motion and adjacent level degeneration after lumbar total disc replacement. Spine J 2006;6:242-7.

[28] Ensink FB, Saur PM, Frese K, et al. Lumbar range of motion: influence of time of day and individual factors on measurements. Spine 1996;21:1339-43.

[29] Pearcy MJ, Bogduk N. Instantaneous axes of rotation of the lumbar intervertebral joints. Spine 1988;13:1033-41.

[30] Rousseau MA, Laporte S, Dufour T, et al. Three-dimensional assessment of the intervertebral kinematics after Mobi-C total disc replacement at the cervical spine in vivo using the EOS stereoradiography system. SAS J 2011;5:63-8. 